\title{
The purpose of modem land management in the organization of agricultural land use for sustainable socio-ecological and economic development
}

\author{
Marina Podkovyrova ${ }^{1, *}$ and Dmitriy Kucherov ${ }^{1}$ \\ ${ }^{1}$ Industrial University of Tyumen, 625001, Tyumen city, Russia
}

\begin{abstract}
Theauthors examined the key components of In moden post reform conditions when the organization of the use of agricultural land is carried out without land management project documentation and relevant recommendations, in conditions of significant pressure from industrial and urban development, this is primarily the main reason for the decline in soil fertility and the development of degradation processes, a departure from the classical sustainable agricultural land use, formed on the principles of land management and the laws of nature management [1-4]. In the process of functioning, once-stable land uses have not changed borders for decades, which indicates a rational overall size of agricultural land use, when all three production factors: "labor", "land" and "capital" are in full compliance with each of them, that is, harmonization, rationalization and greening $[5,6]$. This harmonization eliminates the presence of such disadvantages as: far-earth, cross-stripe, wedging, etc., creates conditions for the rationai organization of the use of agricultural land $[2,5,6]$.
\end{abstract}

\section{Introduction}

The works of well-known Russian scientists S. A. Udachin, E. B. Dopiro, N. N. Burikhin, A.D. Shuleikin, M. A. Gendelman, V. D. Kiryukhin, S. N. Volkov, M. A. Sulin, Yu. M. Rogatnev, Z. F. Kochergina, V. I. Bryzhko, D. V. Novikov, and many others are devoted to the issues of rational organization of the use and protection of agricultural land.

But with significant transformations in the field of land and property relations, the scale of industrial development, today in the system of functioning of agricultural land use, there is a massive fragmentation of land massifs; difficulties in forming (organizing) agricultural land uses that lack prospects for rational organization of land use and protection; reduction of valuable agricultural land due to their overgrowth with tree and shrub vegetation, waterlogging; reduction of soil fertility due to the use of monocultures and complete violation of the scientifically-based crop rotation system; reduction of organic fertilizer application; crisis in the field of land reclamation (irrigation, drainage, control of soil salinization); failure to manage the use of land resources; the exclusion of the role of land management, the importance of land management schemes of municipal districts and

\footnotetext{
* Corresponding author: podkovyrova.54@mail.ru
} 
projects of on-farm land management, which requires, on the one hand, the development of new land management documentation, on the other hand, the preservation of centuries-old experience in caring for natural resources, including land resources, the development of new regulatory and legislative acts that consolidate the norms, principles and tools for their sustainable development. In this regard, scientific interest is aroused in understanding the purpose of modern land management in the development of the agro-industrial complex of municipal districts and regions as a whole, based on an adaptive, socio-ecological and economic approach to the formation of sustainable agricultural land use, which meets the principles of full compliance with economic activities, legal criteria, economic and labor resources, and the ecological state of natural and economic systems [2-4, 6-10].

\section{Materials and methods}

Based on this goal, the authors of the article propose the following research methodology $[2,4,6-8,10]$ :

1. Study of the purpose, goals, objectives and content of land management schemes of municipal (administrative) districts, projects of on-farm land management in the modern process of planning the development of territories.

2. Analysis of the current system of normative and legislative acts that ensure the organization of agricultural land use and the organization of the use of agricultural land.

3. Analysis of the state and use of agricultural land within the boundaries of agricultural municipal districts and agricultural land uses.

4. Analysis of the state and content of the scientific and methodological component of land management design at the modern post-reform stage of the functioning of agricultural land use.

5. Development of the methodology of the land management project for the rational organization of the use of agricultural land use on a landscape-ecological basis.

The agricultural land use of CJSC "Plemzavod-Yubileyny" of the Abatsky municipal district of the Tyumen region was accepted as the object of research. The article presents in more detail the developments concerning the landscape and ecological basis of the land management project "Rational organization of the use of agricultural land use", which ensures its sustainable development. The study covers the methodology of accounting for soil suitability classes and landscape-ecological mapping. In the course of the research, the following project tasks were solved $[2,4,6,10]$ :

1. The features of the formation, socio-economic development of the economy and the organization of the use of agricultural land are studied.

2. The analysis of the ecological state of agricultural land is carried out.

3. The soil suitability classes are established.

4.The analysis of the existing organization of the use of agricultural land is carried out.

5. The degree of ecological and economic condition of agricultural land is established.

6. Ecological and economic mapping of the territory of agricultural land use was carried out, a set of thematic maps on the topic of the study was presented.

7. The project of rational organization of land use of CJSC "Plemzavod-Yubileyny" on a landscape-ecological basis has been developed.

When developing the project, the authors used the following methods: abstract-logical, analyzing hierarchies, modeling, computational-variant, thematic mapping. 


\section{Results}

Optimization of agricultural land use is associated with the use of the method of hierarchy analysis, a landscape-ecological approach that combines the analysis of both natural and anthropogenic factors that affect soil fertility and the economic efficiency of production $[2$, $5,6,10,12]$. When using the landscape-ecological approach on the example of the studied land use, an information and analytical basis has been developed, consisting of an analytical block and specialized maps that allow developing an optimization territorial model of agricultural land use, taking into account economic, social, physical-geographical, agroecological, soil-erosion and other factors that reflect the state of the studied land use $[2$, $5,6,10]$ :

1. According to the method of Kochergina Z. F., a landscape-ecological assessment of agricultural land was carried out, as a result of which one of the information resources "Landscape-ecological conditions of the state of agricultural land use"was formed.

2. The classes of soil suitability were identified, the basis was the possibility of appropriate use of land in relation to the types of agricultural land: arable land, pastures and hayfields. On the territory of the studied land use, the soils are represented by three classes of suitability (Table 1):

1) The second class of suitability is typical for lands suitable for arable land with restrictions on use, requiring measures aimed at increasing fertility, improving waterphysical and other properties of the soil (chernozems, gray forest, meadow, chernozemmeadow soils and solonets).

2) The third class is represented by land suitable for forage land that does not require restrictions in their use (chernozem and meadow soils).

3) The fourth class includes land that is limited suitable for forage land (saline and meadow-swamp soils).

Table 1. Characteristics of agricultural land suitability classes.

\begin{tabular}{|l|c|c|c|c|c|}
\hline \multirow{2}{*}{ Land area } & \multicolumn{5}{|c|}{ Suitability classes of agricultural land and its area, ha } \\
\cline { 2 - 6 } & $\mathbf{1}$ & $\mathbf{2}$ & $\mathbf{3}$ & $\mathbf{4}$ & $\mathbf{5}$ \\
\hline Arable land & - & 2600 & 1000 & 298,7 & - \\
\hline Haymaking & - & - & 1964 & 2752,73 & - \\
\hline Pasture & - & - & 2650 & 2452,42 & - \\
\hline Total agricultural land land & - & 2600 & 5614 & 5503,55 & - \\
\hline
\end{tabular}

3. The analysis of the existing organization of the use of agricultural land is carried out:

1) The arable areas of the farm under study are used for monoculture (wheat) - a change in the structure of field crop rotations is required.

2) The current system of the field road network, which has defined the boundaries of crop rotation fields, indicates that the fields are not equal in area, and the inclusion of heterogeneous soils in the fields (54\%) confirms that they are not equal in gross output (68\%)-it is necessary to organize the use and engineering arrangement of arable land on the basis of the development of a land management project.

3) The direction of cultivation of crop rotation fields does not meet the requirements (the degree of protection of crop rotation fields from wind and water erosion is $27 \%$ )-it is necessary to organize the use and engineering arrangement of arable land on the basis of the development of a land management project.

4) Pasture lands are subject to moderate and severe salinization-it is necessary to develop design solutions for the organization of the use of pasture turnover.

5) Hayfields are interspersed, subject to salinization and waterlogging-it is necessary to develop design solutions for the organization of the use of hayfields. 
4. Ecological mapping was performed, reflecting the structure and properties of agricultural landscapes, the ecological state of the land (Table 2, Figure 1). The following set of specialized maps using GIS technologies has been developed (Table 2).

Table 2. Set of specialized cards.

\begin{tabular}{|l|l|}
\hline \multicolumn{1}{|c|}{ Map } & \multicolumn{1}{|c|}{ Appointment } \\
\hline Map of anthropogenic landscapes & $\begin{array}{l}\text { Study (analysis) structures of anthropogenic } \\
\text { landscapes }\end{array}$ \\
\hline Map of agricultural landscapes & $\begin{array}{l}\text { Analysis of the morphological structure of } \\
\text { agricultural landscapes }\end{array}$ \\
\hline Soil map & Soil condition analysis \\
\hline $\begin{array}{l}\text { Map of ecological and economic zoning } \\
\text { of land }\end{array}$ & $\begin{array}{l}\text { Establishment of land use regimes for agricultural } \\
\text { land use }\end{array}$ \\
\hline $\begin{array}{l}\text { Map of ecological and economic zoning } \\
\text { of land by class of soil suitability }\end{array}$ & $\begin{array}{l}\text { Allocation of zones relative to the intended use of } \\
\text { soils (land) }\end{array}$ \\
\hline $\begin{array}{l}\text { Project of rational organization of } \\
\text { agricultural land use (optimization } \\
\text { model of agricultural land use) }\end{array}$ & $\begin{array}{l}\text { The basis for the development of project proposals } \\
\text { for improvement, landscape and environmental } \\
\text { optimization and rational organization of the use of } \\
\text { agricultural land }\end{array}$ \\
\hline
\end{tabular}

As a result of the study, it was found that negative processes in the territory of the studied land use are manifested in a weak degree-29\%, an average degree-33\% and a strong degree-38\%. As for the ecological and economic use, the following zones are established during the ecological mapping:

- zone of intensive agricultural use (the area of the zone is 6106.41 hectares, this zone assumes any permitted use);

- -zone with restrictions in land use (area 5585 ha includes areas: medium-eroded, medium-washed, medium-saline);

- restoration zone (5093 ha) with improvement subzone. The recovery zone involves special measures (improvement, transformation);

- conservation area (in the northern and north-western agricultural land use area, with an area of 1,634 ha), see figure 1 . 


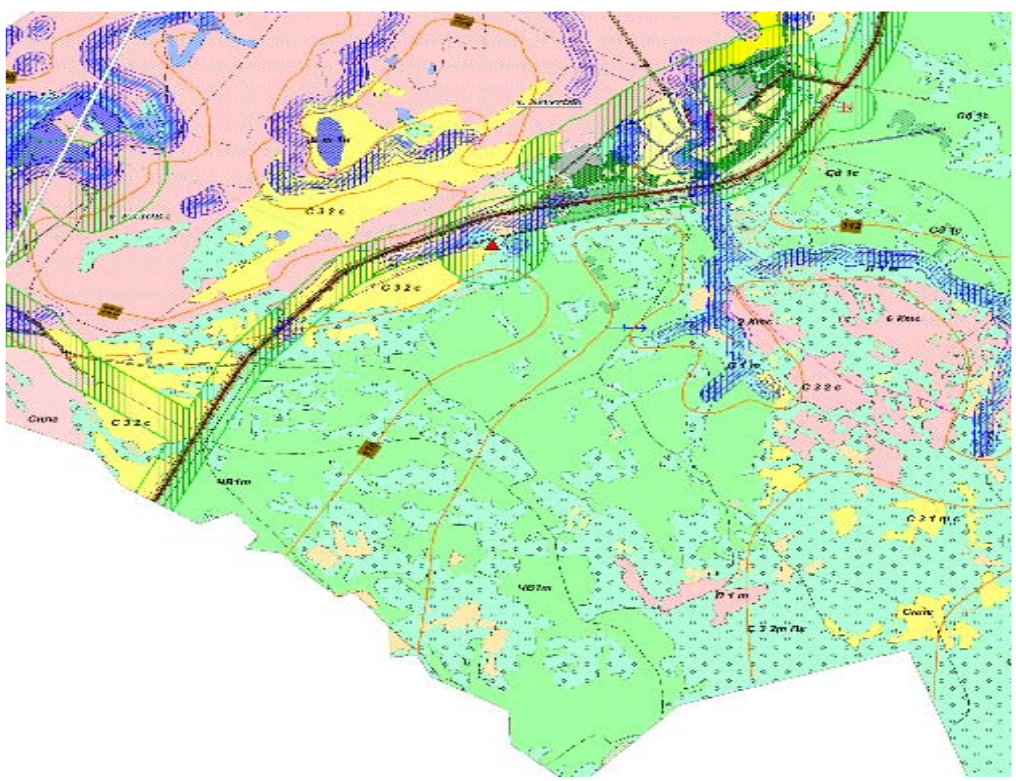

LEGEND

LANDSCAPE-ECOLOGICAL ZONES AND THEIR BORDERS

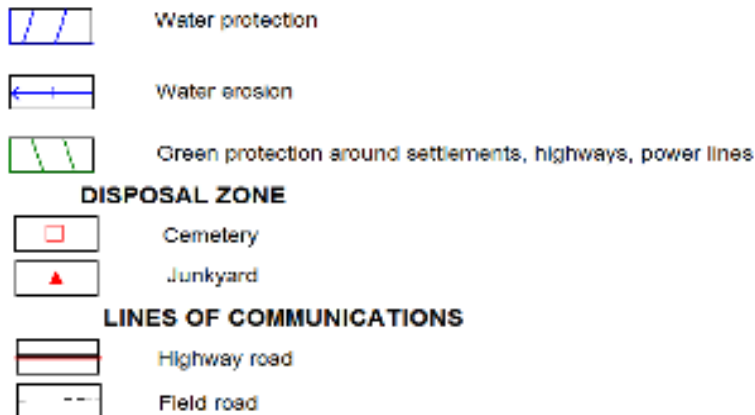

Fig. 1. Fragment of the scheme of ecological and economic mapping of the territory of agricultural land use (author's developments).

The formed ecological and economic zones on the territory of the farm are the basis for the development of the "Project for the rational organization of the use of agricultural land of CJSC Plemza-vod-Yubileyny", which provides for the rational organization of the use of land and the development of appropriate land management, agrotechnological and land reclamation measures (Figure 2) [2- 4, 6-8, 10]. 


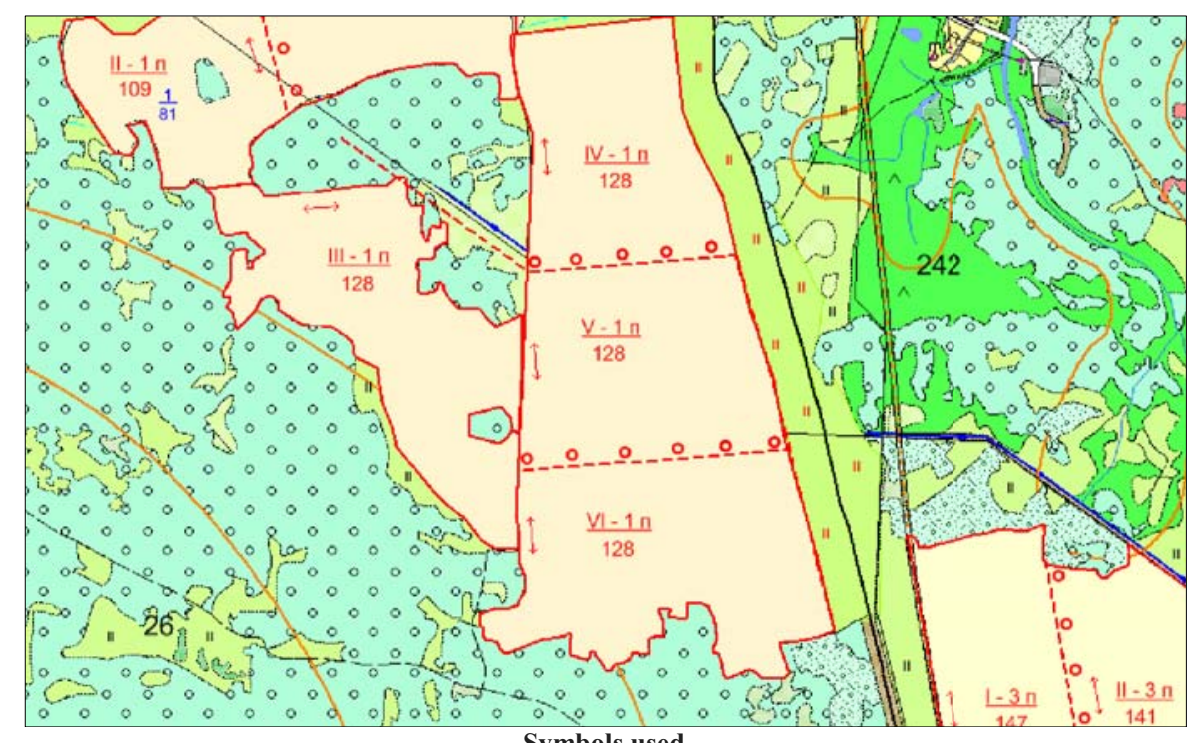

Symbols used

$\frac{1-1 \pi}{200} \quad$ Field crop rotation (field number, crop rotation number, field area)

Fig. 2. Fragment of the project of rational organization of land use on a landscape-ecological basis (author's developments).

The project of rational organization of the use of agricultural land of CJSC "PlemzavodYubileyny" contains:

1. The developed system of crop rotations taking into account the established degree of ecological tension of arable land: field crop rotations are preserved, clean steam is transferred to occupied; soil-protective crop rotations with a ratio of cereals and grasses (50 $\%: 50 \%$ ) are introduced.

3. Improved system of fields, field roads and four-row protective forest stands $(12 \mathrm{~m}$ wide).

4. The volume of improvement, transformation and conservation of agricultural land, their landscape and environmental optimization.

The economic efficiency of project activities is determined by the growth of net income, the efficiency coefficients of capital investments for a number of activities vary from 0.37 to 0.49 . The payback period does not exceed the standard indicators.

\section{Discussion}

The implementation of this methodology will allow, on the basis of a comprehensive analysis and accounting of the existing organization of the use and condition of land, economic and labor resources in the near future, to determine the degree of ecological and economic condition of agricultural land and on this basis [2, 5, 6, 10, 11, 13]:

- optimize the production factors of the economy;

- regulate land use regimes based on their natural properties, anthropogenic state and soil suitability classes;

- determine the natural resource potential of the economy involved in agricultural production;

- develop a system of environmental measures for the conservation, restoration, and improvement of agricultural land; 
- to form the land use of sustainable socio-ecological and economic development (to optimize agricultural land use);

- implement the principle of rational organization of agricultural land use and the laws of balanced nature management.

\section{Conclusion}

The established practice confirms that landscape-ecological (ecological-economic) approaches to the organization of the use of agricultural land ( agricultural land), their landscape and environmental optimization should be implemented in both large and small agricultural enterprises, based on the inventory and monitoring of the state and use of land, which will provide an innovative approach to the:

- processes of organizing production; - using and preserving land resources;

- cultivating crops;

- raising livestock and poultry;

- increasing soil fertility;

- forming agroforestscapes;

- reducing the processes of salinization, waterlogging, water and wind erosion, and this means that the development of the agro-industrial complex of the regions is sustainable from an economic, social and environmental point of view, which confirms the relevance of the study $[2,6-8,10,14,15]$.

\section{References}

1. I. Binder, A. Oleynik, M. Podkovyrova, A. Piterskikh, I. Golubev, Landscape and environmental analysis and anthropogenic disturbance of the Varandey oil field (The Mattingley Publishing Co., Inc., 2019)

2. M. Podkovyrova, N. Ivanova, D. Kucherov, International agricultural journal 2, 202211 (2020) DOI: 10.24411/2588-0209-2020-10165

3. M. Podkovyrova, N. Ivanova, O. Volobueva, E. Volobuev, Materials Science and Engineering 918, 012225 (2020) DOI :10.1088/1757-899X/918/1/0122255

4. M. Podkovyrova, A. Plotnikov, V. Tolstov, International agricultural journal 1 (2021) https://iacj.eu/index.php/iacj/article/view/345

5. S. Volkov, Land management, cadastre and monitoring of land 8, 4 (2006)

6. Z. Kochergina, Landscape-ecological fundamentals of rationalization of land use (based on materials from the forest-steppe zone of the Omsk region), https://search.rsl.ru/ru/record/01003538949

7. A. Zhelyaskov, N. Shaldunova, Land management, cadastre and land monitoring 3, 1820 (2007)

8. A. Zhelyaskov, N. Denisova,Land management, cadastre and land monitoring 10, 2833 (2011)

9. M. Podkovyrova, N. Ivanova, Economics of agriculture of Russia 33(11), 80-86 (2019)

10. D. Kucherov, A. Rutz, Optimization model of agricultural land use on the example of Plemzavod-Yubileyny CJSC Geodesy, Land Management and Cadastre (OmGAU, Omsk, 2017)

11. E. Winfried, Soil indicators for decision making - sharing knowledge between science, stakeholders and politics (Blum, 2002) 
12. A. Ishizaka, A. Labib, Analytic hierarchy process and Expert Choice: benefits and limitation 24, 201-220 (2009)

13. V. Belton, T. Stewart, Multiple criteria decision analysis. An integrated approach, https://cyberleninka.ru/article/n/analiz-ierarhicheskih-mnogokriterialnyh-zadachprinyatiya-resheniy-metodami-teorii-vazhnosti-kriteriev

14. M. Podkovyrova, A. Oleinik, A. Matveeva, International Journal of Civil Engineering and Technology 9, 513 (2018)

15. T. Durrant, R. Hiedever, Environmental monitoring 11, 774-781 (2009) DOI: $10.1039 / \mathrm{b} 81827$ 